\title{
Multidimensional Benefits of Sustainable Agriculture Practices of Cambodian Smallholder Farmers
}

\author{
Camille Heylen ${ }^{1}$, Félicien Meunier ${ }^{1}$, Amaury Peeters ${ }^{2}$, Sreykhouch $\mathrm{Ek}^{3}$, Malyne Neang $^{3}$, Saray $\mathrm{Hean}^{4}$ \& Sinal \\ Peanh $^{4}$ \\ ${ }^{1}$ Earth and Life Institute, Environment, Université catholique de Louvain, Belgium \\ ${ }^{2}$ Louvain Coopération au Développement, Louvain-la-Neuve, Belgium \\ ${ }^{3}$ Ecoland Research Center, Royal University of Agriculture, Phnom Penh, Cambodia \\ ${ }^{4}$ Minority Organization for Development of Economy, Kampong Thom, Cambodia \\ Correspondence: Camille Heylen, Earth and Life Institute, Environment, Université catholique de Louvain, \\ Belgium. E-mail: camille.heylen@gmail.com
}

Received: October 6, 2019 Accepted: November 2, 2019 Online Published: November 26, 2019

doi:10.5539/sar.v9n1p10 URL: https://doi.org/10.5539/sar.v9n1p10

\begin{abstract}
Agriculture is an important mainstay of the Cambodian economy and recent agriculture developments have lifted many people out of poverty. However, some key challenges remain in Cambodian rural areas. To further sustain the country's development, new ways need to be found to drive future growth without negatively impacting its existing resources. Recent efforts led by development stakeholders have been dedicated to enhanc the sustainability of Cambodian agriculture. The local non-governmental organization MODE jointly with Louvain Cooperation focuses on helping vulnerable farmers to transition towards sustainable agriculture practices through specific training. This paper aims to assess the benefits of such an approach by using SAFA (Sustainability Assessment of Food and Agriculture systems), a methodology developed by the Food and Agriculture Organization. Core indicators of the four pillars of sustainability were evaluated through interviews with eighty farmers, equally distributed in two groups (target farmers and a control group), to assess the agricultural sustainability of their local farming system.

Statistical analysis revealed significant differences between the two groups. The target group which was supported in their transition to sustainable practices showed a significant increase of net incomes, more diverse food production, and higher number of actions already taken or planned in order to mitigate the inherent risks of food production. The global index resulting from the combination of all core indicators revealed a significant difference between the groups, with more sustainable practices for the target farmers. However, overall the level of sustainability remained low to very low in both groups, which was partly due to the choice to work with vulnerable people defined by low productivity.
\end{abstract}

Keywords: sustainable agriculture, project impact assessment, agricultural training, SAFA, Kampong Thom, Cambodia
Abbreviations
FAO : Food and Agriculture Organization
GDP : Gross Domestic Product
LC : Louvain Cooperation
MODE : Minority Organization for Development of Economy
NGO : Non-Governmental Organization
RUA : Royal University of Agriculture
SAFA : Sustainability Assessment of Food and Agriculture systems

\section{Introduction}

Sustainable agriculture can be defined as "the management and conservation of the natural resource base, and the 
orientation of technological change in such a manner as to ensure the attainment of continued satisfaction of human needs for present and future generations. Sustainable agriculture conserves land, water, and plant and animal genetic resources, and is environmentally non-degrading, technically appropriate, economically viable and socially acceptable" (FAO 1989). Sustainability in agriculture is often aggregated as the combination of four goals: the right quality of life for farmers, workers and the society as a whole; the economic viability of agriculture; the environmental respect of the resources; and the satisfaction of human needs for food and by-products (FAO 2017; 2013). Nevertheless, it encompasses so many distinct aspects and remains such a composite concept that there is no agreement on its exact definition, scale and components (Hayati, Ranjbar, and Karami 2010).

In recent decades, numerous and various methods assessing either particular pillars of sustainability or sustainability as a whole have been developed at different spatial scales and for various objectives (see among many others: Lebacq, Baret, and Stilmant 2013; Latruffe et al. 2016; Paracchini et al. 2015). Many of them were suggested as the reference framework for studying the agricultural sustainability. The rationale to specifically choose one method over the others relies on the specific context of the study, even though several approaches such as the MESMIS operative structure aim to be holistic and context-independent (López-Ridaura 2002). They are all based on the assessment of one or several agriculture-related indicators.

Over time, several typologies have been presented to organize these indicators based on the causality between the farming practices and their impacts (Bockstaller et al. 2009), which can also depend on external factors, such as soil properties or climate (Lebacq, Baret, and Stilmant 2013). Three main categories of indicators exist: i) means-based indicators depending on farmer production practices; ii) effect-based indicators evaluated through direct measurements of the effects these practices have on the surrounding world (van der Werf and Petit 2002; van der Werf, Kanyarushoki, and Corson 2009); and iii) target-based indicators that focus on whether the operation has plans or policies with clear targets and steps towards implementing them (FAO 2013). The first class of indicator focuses on the best practices and is process-oriented assuming that good practices systematically lead to the desired results (FAO 2013). The second category is outcome-oriented with a clear link between the objectives and the measured indicators. This approach leaves the farmers or the considered stakeholders free to choose the best means to reach the sustainable goals according to their specific context. Finally, the target-based indicators look for a systematic vision and policy for the future of the farm oragricultural company. Each type of indicator suffers from intrinsic drawbacks, such as their substantial margin error (means-based), their measurement cost (effect-based) or their remoteness with the present (target-based) (van der Werf and Petit 2002). To mitigate their biases and overcome these limits, the indicators are often compiled into indexes on the basis of an underlying model, allowing researchers to measure multidimensional concepts that cannot be captured by single indicators alone (OECD 2008). Sustainability in agriculture is particularly relevant to be assessed by composite indicators because of its intricacy and multidimensional complexity.

The Food and Agriculture Organization (FAO) created a holistic and global framework for the assessment of sustainability along food and agriculture value chains by establishing an international reference for assessing trade-offs and synergies between all dimensions of sustainability (FAO 2013), called the Sustainability Assessment of Food and Agriculture systems method (SAFA). As many of the strategies to measure the agricultural sustainability, SAFA is based on individual assessments of certain key-aspects of the food production and processing (Gayatri, Gasso-tortajada, and Vaarst 2016; Jawtusch et al. 2013). Indicators-based sustainability assessment tools are generally structured following three or four hierarchical levels (de Olde et al. 2016). In SAFA, the indicators (lowest level) aim to reflect the different components of four pillars (highest level) defining the sustainability: good governance, environmental integrity, social well-being, and economic resilience (FAO 2013). The SAFA method lists themes for all pillars and provides core indicators for each single sub-theme, thus further subdividing the considered theme (see Figure A.1 in Appendix for a schematic view of the hierarchical levels). The indicators may fall into any of the three categories aforementioned (means-, effect- or target-based) according to the assessed aspect and the corresponding relevance or appropriateness. SAFA is applicable globally and is relevant for each component of the value chain. The methodology was successfully applied to the food processing sector in Czech Republic (Hřebíček et al. 2015), to beef cattle farming in Indonesia (Gayatri, Gasso-tortajada, and Vaarst 2016), to certification of banana agri-food systems (Bonisoli et al. 2019) or at larger scale to Paraguayan agriculture (Soldi et al. 2019). In this article, we applied it to the smallholder farmers of Cambodia's Kampong Thom province, a category of population that experiences profound, systematic and rapid changes.

In Cambodia, agriculture is one of the traditional mainstays of the economy, accounting for around $22 \%$ of the 
GDP in 2018 (The World Bank 2018). About 80\% of households live in rural areas and are engaged in some agricultural activities, with an average land holding of 1.6 hectare per family (National Institute of Statistics 2014). Cambodia has experienced a rapid growth of the agriculture sector in recent decades and correspondingly, a profound transformation of the rural society (The World Bank 2015). However, agricultural practices remain mostly traditionally extensive, even though intensification chaotically appears in some regions with a recent boost in fertilizers consumption and a slow but steady increase of food production (FAO 2018). Most smallholder farmers use agriculture to meet their consumption needs and cultivate almost exclusively rice using traditional farming practices (Diepart 2010; Srean et al. 2018). Small and variable (depending on seasonal weather conditions) production makes farmers extremely vulnerable economically (Royal Government of Cambodia, and Ministry of Planning. 2013). In addition, many producers in Cambodia already perceive the impacts of climate change (Bansok, Phirun, and Chhun 2011), with extended drought and flooding predicted in the near future that might affect yield(WHO Representative Office Cambodia 2019; Yusuf 2010; Miyan 2015).

Farmers in Kampong Thom province produce mainly rice and cassava (National Institute of Statistics 2014), ranking in the top 10 of provinces (out of 25) in terms of growing crops and raising livestock and poultry: the total agricultural area is 195,000 ha, without taking into account home-lot agricultural surfaces, an important element for smallholder farmers. In this province shaped by agriculture, several local, regional, national and international stakeholders work together with smallholder farmers to enhance the sustainability of food production (Royal Government of Cambodia, and Ministry of Planning. 2013), including MODE (Minority Organization for Development of Economy), a Cambodian Non-Governmental Organization (NGO) which works jointly with the technical support of Louvain Cooperation (LC) on training programs for local farmers to encourage the development of sustainable agriculture practices and,new farming production systems, and to diversify their sources of income. Targeted smallholders are vulnerable farmers (i.e. farmers with low yields and incomes, or farmers whose families are mono-parental or include disabled or chronically ill people) in eight communes of Kampong Thom province. The seven day training session they attend on sustainable agriculture includes theoretical classes, field demonstrations and agricultural kits distribution to enhance the food production system of farmers in order to increase their incomes. The training sessions and corresponding information kits encompass topics related to food diversification and farming systems: good practice in chicken raising; system of rice sustainable intensification methods for developing aquaculture production; methodology for composting and cultivating vegetables in house gardens; lessons for edible fruit tree planting; and food processing. Regular formal and informal follow-ups are organized by local field facilitation teams for several months, with the frequency and total number of visits depending on the implementation of the recommended practices; but at least three formal monitoring visits are devoted to each farmer. Informal meetings consist of gathering participants to reinforce their knowledge through communication and collaboration activities. The project started in 2011 and 1,000 farmers benefited by 2016 from the interventions.

To monitor the impacts of the overall project, a scientific framework to assess the agricultural sustainability and compare the target group practices with other similar farmers was mandatory. We chose to apply the SAFA framework because of the exhaustiveness, robustness and flexibility of the method (FAO 2013). The objectives of this research were: (i) defining a methodology to assess the sustainability adapted to the rice-oriented farming production system of Kampong Thom province, Cambodia; (ii) quantitatively comparing the food production sustainability of smallholder farmers who benefited from project support and those who did not; and (iii) assessing the overall level of sustainability of local smallholder farmers.

\section{Material and Methods}

To assess the impact of the interventions promoting sustainable agriculture practices by MODE/Louvain Cooperation in Kampong Thom province, we used the SAFA framework developed by the FAO (2013), adapted to the local farming system (section 2.1). The study was based on structured quantitative and qualitative interviews carried out with smallholder farmers from the project (target) and other similar farmers (control) (section 2.2), whose sampling is further explained in section 2.3.

\subsection{Indicators Selection}

We primarily selected themes and sub-themes of the SAFA methodology according to their relevance to the local context of the current farming systems in Kampong Thom (Appendix A, Table A.1), following both FAO recommendations (a complete description of the procedure can be found in the SAFA guidelines (FAO 2013)) and discussion with local experts from NGOs directly involved in the implementation, namely Louvain Cooperation, active in the region since 2004, MODE, and a local academic from the Royal University of Agriculture (RUA) of Phnom Penh, Cambodia. For each theme and sub-theme, we defined if it was directly 
linked to the sustainable agriculture development project in Cambodia (+, see Appendix A, Table A.1), if it was considered as absent from the current project objectives list (-) or if it was currently not considered by the project but could be included in future application plans (o), according to the main project leaders and project proposals. Comparing the universal themes and the specific sub-themes within the local context and the objectives of the project, 18 themes (out of 21), 35 (out of 56) sub-themes and 53 (out of 105) core indicators were retained from the original list of the SAFA framework (the comprehensive list of SAFA indicators is presented in Table A.2). Most of the omitted indicators were part of the governance pillar. Thirty core indicators were conserved in the environmental pillar, 12 in the economic pillar, 8 in the social pillar and 3 in the good governance pillar and were evaluated through questionnaires whose design is explained in the next section. Such a strategy (SAFA adaptation through questionnaires) has been successfully applied in different contexts globally, see for example Gayatri (2016).

\subsection{Interview}

Based on the selection of the indicators, a structured questionnaire was developed including sections on general socio-economic information of the household, land distribution, farming practices, economic status, perception of the risks threatening the enterprise (as listed by local actors, i.e. field facilitators, local NGO members and university professors, as well as the SAFA recommendation) and perspectives in a changing world. The questionnaire was optimized to maximize the number of measured indicators under constraints of time and length of the interview (approximate duration of 2-3 hours) and complexity of some concepts. The questionnaire was iteratively translated into Khmer, improved and corrected through on-field tests on volunteer farmers (both target and control groups were tested at this stage, see next paragraph for group definition). Among the questions asked, a list of risks that could threaten the enterprise was presented, following input from local specialists from NGOs, the RUA, and local field facilitators based on their experience. These risks were then systematically submitted to each interviewee for acknowledgment by the farmer of its potential negative impact. For each recognized risk, interviewees also had to explain how they are or would be fighting it in the future to avoid negative consequences for their farm. Among their answers, we only selected relevant actions based on FAO recommendations or literature to assess their capacity of resilience. These interviews were conducted in Khmer by the local project staff assisted by students from the RUA during October 2016.

\subsection{Sampling}

We selected a panel of 80 farmers equally divided in two groups: a target group of farmers who benefited from the project interventions, and a control group of other similar smallholder farmers. Interviews took place in eight villages selected among five representative communes, all located in Kampong Thom province. The villages were chosen because they house some of the first project recipients who were trained and followed up (even though for some of the interviewees the training received was rather recent). Therefore, they were also the most susceptible to present significant differences in terms of farming practices or results. An equal number of interviewees were selected in each village among the two groups. The corresponding numbers were chosen according to the ratio of total number of target farmers in each village with respect to the global number of farmers targeted by the project since its beginning.

The eight villages are highlighted with red dots in Figure 1, among the other villages where interventions occur ( black dots), along with the location of Kampong Thom province in Cambodia (bold dark solid line in the frame). The first five communes where the project started (red solid lines for both the frame and the principal figure) are also represented. 


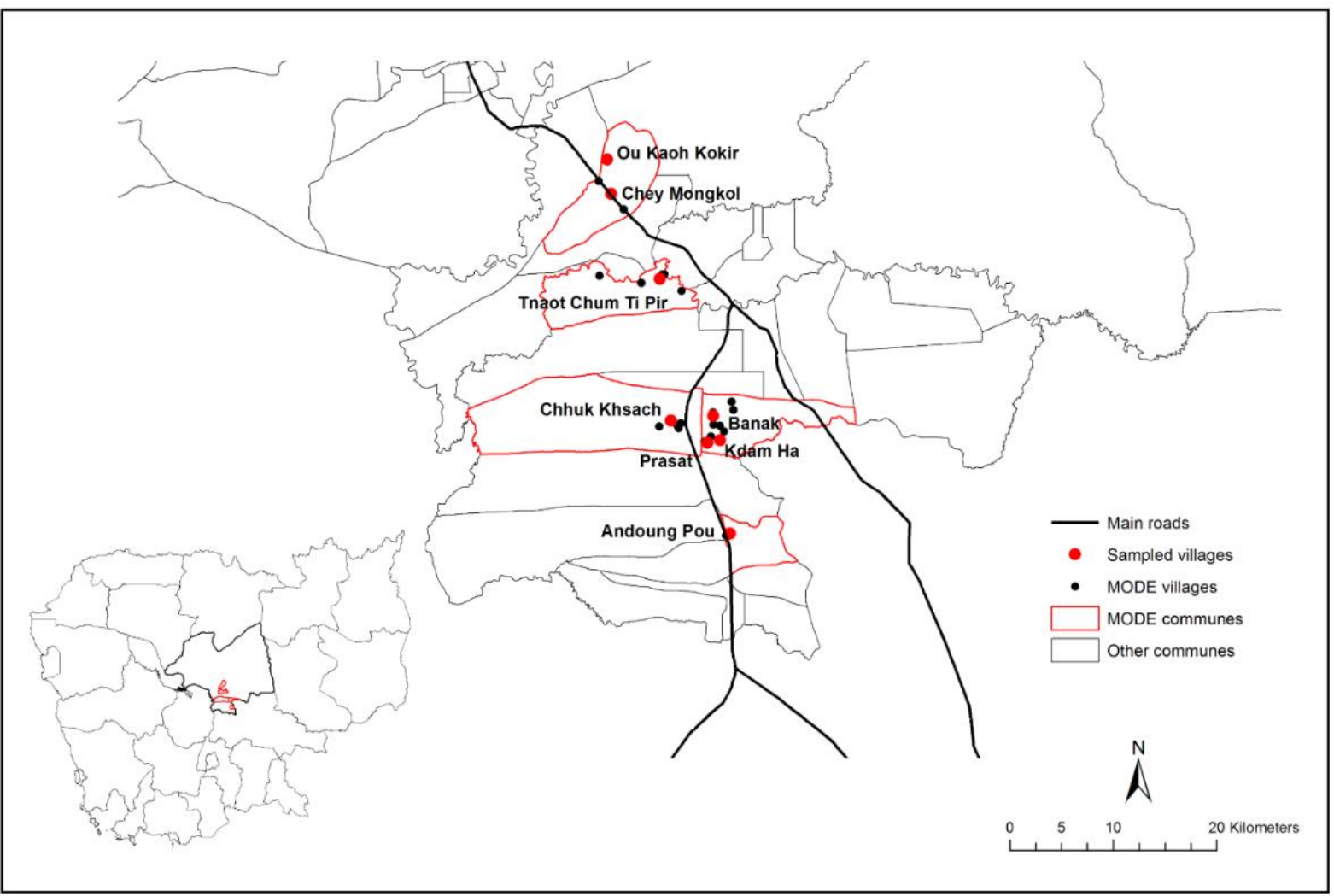

Figure 1. Location of the sampled communes (red lines) and villages (red dots). In this map, the other villages where interventions also happen are indicated with dark points. The global location of Kampong Thom province in Cambodia is indicated in the lower left corner

Table 1 summarizes the name of the sampled villages and the corresponding number of interviewees by village for both the systematically identical target and control groups.

Table 1. Sampled villages and number of interviewees for target and control groups

\begin{tabular}{lll}
\hline \multirow{2}{*}{ Village } & \multicolumn{2}{l}{ Number of interviewees } \\
\cline { 2 - 3 } & Target Group & Control Group \\
\hline Andoung Pou & 10 & 10 \\
Ou Kaoh kohir & 6 & 6 \\
Banak & 3 & 3 \\
Chey Mongkol & 7 & 7 \\
Chhuk khsach & 3 & 3 \\
Kdam ha & 4 & 4 \\
Prasat & 5 & 5 \\
Thnaot Chum Ti Pir & 2 & 2 \\
\hline
\end{tabular}

One of the main challenges of the methodology was to select control farmers at a level of vulnerability similar to the farmers selected for the project: a bias could be introduced by systematically interviewing farmers at higher vulnerability levels. To do so, a preliminary and dedicated set of screening questions were developed, which allowed the interviewers to select control farmers on the basis of their main job, income sources and land size. These questions were typically used for selecting potential project recipients when targeting a new village. When randomly contacted, farmers responded to similar criteria as the ones usually benefiting from the project and they were included in the control group for analysis. The similarity of both groups was further tested after data collection in terms of family size, distances to main infrastructure (road and water) and farm size in order to ensure they could indeed be compared (see Results section below). Additionally, each target group interviewee had to have been supported for at least one year before the interview took place. 


\subsection{Database and Statistical Analysis}

Interview responses were collected, scanned, translated into English and stored in a database. Quantitative and qualitative responses were used for calculating the core indicators according to the SAFA method. The latter could then be compiled into composite indicators to assess the different hierarchical levels of sustainability as defined in the FAO methodology from sub-theme to pillar (and even overall) levels. At all levels, the sustainability indexes are normalized to be comprised between 0 (least sustainable) and 1 (most sustainable). Analysis of variance was achieved using the groups (target $v s$ control) as the explanatory variable (two sample t-tests). Variance homogeneities were systematically tested for quantitative variables, while indicator-weighted means were used to calculate normalized composite indicators at sub-theme, theme, pillar and global levels. All statistical tests were performed using the statistical toolbox of Matlab (www.mathworks.com/products/statistics.html). Note that throughout our complete work, we considered two levels of significance for mean comparison: p-value lower than 0.05 and lower than 0.01 . We indicated significant differences between treatments at these two levels with * and $* * *$, respectively.

\section{Results}

No differences could be observed for the farm size, the family size, or the access to natural resources or facilities (such as access to water or distance to main roads) between the two groups. These results validated the idea that both groups were comparable. Farm size and family structure are indeed very important in the Cambodian countryside for the standard of living. In addition, results indicated that farmers from the control group would be eligible for sustainable agriculture training and therefore should look like the target group before treatment (same baseline).

In Table 2, quantitative variable mean ( \pm standard deviation), maximal and minimal values are presented for the two groups for several key variables. Both groups significantly differed when it came to product diversification, monetary income and farm risk awareness (as assessed by detected risks and measures to mitigate those). On average, the target group produced a significantly larger number of distinct products $(8.1 \mathrm{vs} 5.4$, p-value $<0.001)$. The difference mainly stemmed from an increased number of produced vegetables, a higher number of planting trees, and a more diverse animal husbandry. The p-values for the two latter tests reached the significant $\mathrm{p}$-values $2.10^{-6}$ and $10^{-3}$, respectively. This suggested an increased food production diversity thanks to the adoption of the sustainable agriculture practices lessons and the use of the agricultural kits.

Similarly, the monetary income (calculated as direct money obtained through sales) of the target group was significantly higher than the control one $(\mathrm{p}$-value $=0.048)$. This was a direct consequence of the previous result: more products grown or raised led to more sales. In addition, food production diversity potentially leads to better (i.e. higher) prices for some of the newly grown or raised products, as the products introduced into the production system after training could usually be sold at higher prices ( due to being transformed). Very similar results were obtained for the monetary income per capita as the families did not differ between the two groups: the control group was characterized by a significantly lower income per capita ( $\mathrm{p}$-value $=0.041$ ).

Table 2. Summary of select interview outcomes. Mean, minimal and maximal values as well as standard deviations for different features of the farm are given for both the target and the control groups

\begin{tabular}{|c|c|c|c|c|c|c|c|}
\hline \multirow{2}{*}{ Outcomes } & \multicolumn{3}{|c|}{ Target group } & \multicolumn{3}{|c|}{ Control group } & \multirow{2}{*}{$\begin{array}{c}p \text {-value } \\
\text { p-value }\end{array}$} \\
\hline & Mean $( \pm \mathrm{sd})$ & Min. & Max. & Mean $( \pm s d)$ & Min. & Max. & \\
\hline Agricultural diversity [number or products] & $8.1( \pm 1.8)$ & 3 & 14 & $5.4( \pm 2.1)$ & 2 & 11 & $<0.001^{* * *}$ \\
\hline Monetary income $[\$ /$ month $]$ & $119( \pm 71)$ & 0 & 1067 & $54.9( \pm 79)$ & 0 & 503 & $0.048^{*}$ \\
\hline Number of detected risks [-] & $9.6( \pm 4.6)$ & 1 & 20 & $6.9( \pm 3.3)$ & 0 & 12 & $0.043^{*}$ \\
\hline Number of taken and planned risk mitigation measures [-] & $8.2( \pm 1.3)$ & 2 & 18 & $7.2( \pm 0.9)$ & 0 & 20 & $0.006^{* * *}$ \\
\hline
\end{tabular}

Note. *significant at $\mathrm{P}=0.05$ and $* * *$ significant at $\mathrm{P}=0.01$

The project-recipient group was also much more aware of risks that may threaten the farm and its production. On average, farmers from the target group recognized 9.6 risks (as identified by local partners) against less than 7 for the control group $(\mathrm{p}$-value $=0.043$ ). The additional risks identified by the target group were related to the problem of soil fertility and water quality, the low availability of water resources, climate changes, and the lack of agricultural knowledge. Interestingly, these risks were often discussed during training as problematic or potential threats to the farming enterprise. Lastly, significant differences were found in the number of relevant risk mitigation actions already taken or planned to be taken in the near future (p-value $=0.006$ ), with the target group leading the number of mitigation actions (8.12 vs 7.2). Not surprisingly, these actions were also related to 
the additional risks identified (see above).

Through the analysis of quantitative and qualitative data, 12 core indicators distributed in the four pillars describing the sustainability, were found to significantly differ between the two groups (Table 3). They were distributed as following: five in the environmental integrity pillar, three in the social well-being pillar, two in the economic resilience pillar, and two in the good governance pillar. In each, the target group systematically performed better than the control, with the sustainability index of the core indicator being closer to 1 .

Table 3. Core indicators of the SAFA method that showed significant differences between target and control groups, as revealed by a two samples t-test (p-value) comparing sustainability index means between groups

\begin{tabular}{|c|c|c|c|c|c|}
\hline \multirow[t]{2}{*}{ Dimension } & \multirow[t]{2}{*}{ Theme } & \multirow[t]{2}{*}{ Core indicators (SAFA index) } & \multicolumn{2}{|c|}{$\begin{array}{l}\text { Sustainability index mean } \\
( \pm \mathrm{sd})\end{array}$} & \multirow[t]{2}{*}{$p$-value } \\
\hline & & & Target group & Control group & \\
\hline \multirow[t]{5}{*}{ Environmental integrity } & Atmosphere & GHG mitigation practices (E 1.1.2) & $0.16( \pm 0.12)$ & $0.05( \pm 0.04)$ & $0.041 *$ \\
\hline & Water & Water conservation practices (E 2.1.2) & $0.33( \pm 0.29)$ & $0.16( \pm 0.18)$ & $0.046^{*}$ \\
\hline & Biodiversity & Ecosystem connectivity (E 4.1.4) & $0.63( \pm 0.25)$ & $0.47( \pm 0.26)$ & $0.048^{*}$ \\
\hline & & Diversity of production (E 4.2.4) & $0.84( \pm 0.19)$ & $0.62( \pm 0.23)$ & $<0.001 * * *$ \\
\hline & $\begin{array}{l}\text { Material and } \\
\text { energy }\end{array}$ & Waste reduction practices (E 5.3.2) & $0.37( \pm 0.19)$ & $0.18( \pm 0.19)$ & $0.021^{*}$ \\
\hline \multirow[t]{3}{*}{ Social well-being } & Decent livelihood & $\begin{array}{l}\text { Right of fair access to land } \\
\text { and means of production (S.1.3.1) }\end{array}$ & $0.82( \pm 0.14)$ & $0.54( \pm 0.25)$ & $<0.001 * * *$ \\
\hline & $\begin{array}{l}\text { Human health, } \\
\text { safety } \\
\text { and happiness }\end{array}$ & Public health (S.5.2.1) & $0.65( \pm 0.24)$ & $0.53( \pm 0.15)$ & $0.045^{*}$ \\
\hline & Cultural development & Food sovereignty (S.6.2.) & $0.07( \pm 0.05)$ & $0.01( \pm 0.01)$ & $0.006 * * *$ \\
\hline \multirow[t]{2}{*}{ Economic resilience } & Investment & Long-term profitability (C 1.3.1) & $0.13( \pm 0.15)$ & $0.05( \pm 0.08)$ & $0.048^{*}$ \\
\hline & Vulnerability & Risk management (C 2.4.1) & $0.11( \pm 0.06)$ & $0.07( \pm 0.06)$ & $0.023^{*}$ \\
\hline \multirow[t]{2}{*}{ Good governance } & Rules of law & $\begin{array}{l}\text { Free, prior and informed } \\
\text { consent (G.4.4.1) }\end{array}$ & $0.66( \pm 0.06)$ & $0.58( \pm 0.09)$ & $0.026^{*}$ \\
\hline & Holistic management & $\begin{array}{l}\text { Sustainability management } \\
\text { plan (G.5.1.1) }\end{array}$ & $0.41( \pm 0.26)$ & $0.14( \pm 0.17)$ & $0.002 * * *$ \\
\hline
\end{tabular}

Note. $*$ significant at $\mathrm{p}=0.05, * * *$ significant at $\mathrm{p}=0.01$. The sustainability indexes are comprised between 0 (least sustainable) and 1 (most sustainable).

When gathering the information to a higher hierarchical level, eight sub-themes assessing the overall sustainability were shown to significantly differ between the groups. The corresponding sub-themes are indicated in Table A.1 (Appendix A). Out of these eight sub-themes, six were expected to have benefited from the project and did (capacity building, public health, food sovereignty, public management plan, long-ranging investment, and risk management), while two exhibited unexpected differences (greenhouse gases and resource appropriation).

These group differences in sub-themes led to significant differences in the upper hierarchical level. In total, six sustainability themes showed a significant increase for project beneficiaries: biodiversity, decent livelihoods, cultural development, vulnerability, rule of law, and holistic management (Figure 2). In SAFA, the performance of an indicator, sub-theme, theme or pillar is classified between five categories: from very low sustainable value (red) to very high sustainable value (dark green). The overwhelming majority of the analyzed themes were located in the second most vulnerable class (orange, Figure 2) indicating the low level of sustainability reached by smallholder farming practices in the studied area for both studied groups. Remarkably, all the themes, even when not significant, showed increases for the target group as compared to other vulnerable farmers; with the notable exception of the labor right that includes employment relationships and child labor, and whose mean value was relatively high compared to other sustainability themes (Figure 2). 


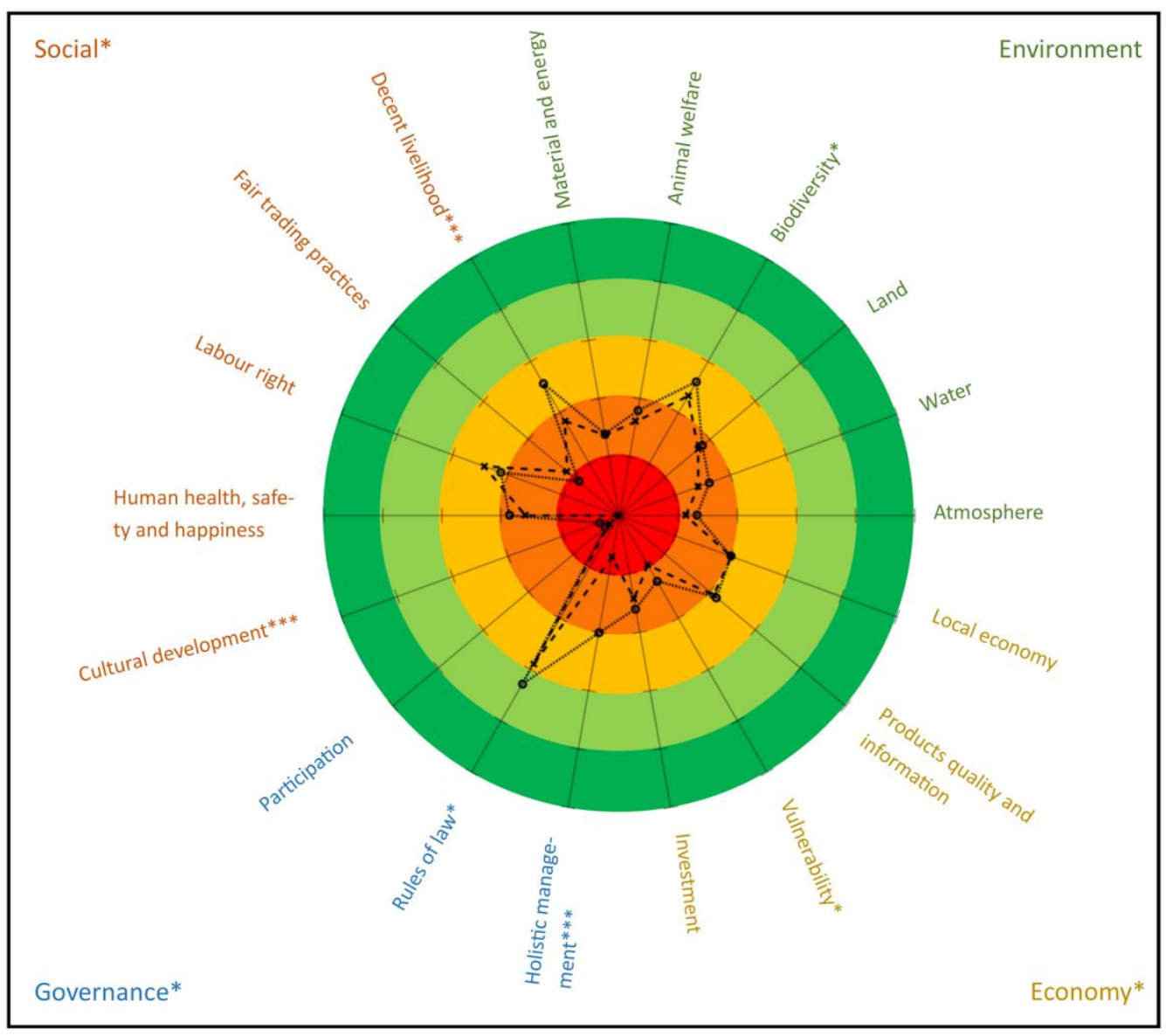

Figure 2. Distribution of the smallholder farmer performances in the four pillars of vulnerability (corners and colors). The theme font color indicates the different pillars (blue $=$ good governance, green $=$ environmental integrity, yellow $=$ economic resilience and red $=$ social well-being). All performances are comprised between 0 (inner red circle, least vulnerable) and 1 (outer dark green circle, most vulnerable). The dotted dark line represents the target group performance while the dashed line shows the control group. When significant differences appear for a specific theme or pillar, it is indicated by the following symbols: * significant at $\mathrm{p}=0.05$, *** significant at $\mathrm{p}$ $=0.01$

The six themes presenting a difference of treatment were found distributed in the four pillars: environmental integrity (one out of the six themes exhibit significant differences), social well-being (2/5), economic resilience (1/4) and good governance (2/3), while the latter three also showed significant differences between the two groups (Figure 2). The environmental integrity did not show statistical differences between the target and the control groups. This could be explained by the fact that even though the largest number of significant indicators belonged to this pillar, the total number of measured indicators of this category was also particularly high, which somehow diluted the significance. The four pillars (despite the significant differences) were characterized by similar levels of sustainability indexes (low).

Finally, when assembled at the highest level (the pillars mixed together into a single composite indicator), the mean value of the global sustainability index (also comprised between 0 and 1) presented a significant difference as well with a small increase for the project beneficiaries (Figure 3). The target group index surpassed the control group index by 0.06 ( $\mathrm{p}$-value $=0.0258$ ). The colors represent the pillar components of the index with the same color legend as the previous figure. Their respective relative contributions to the global sustainability index were substantially the same (not significant differences between the relative contributions of the pillars for each group). 


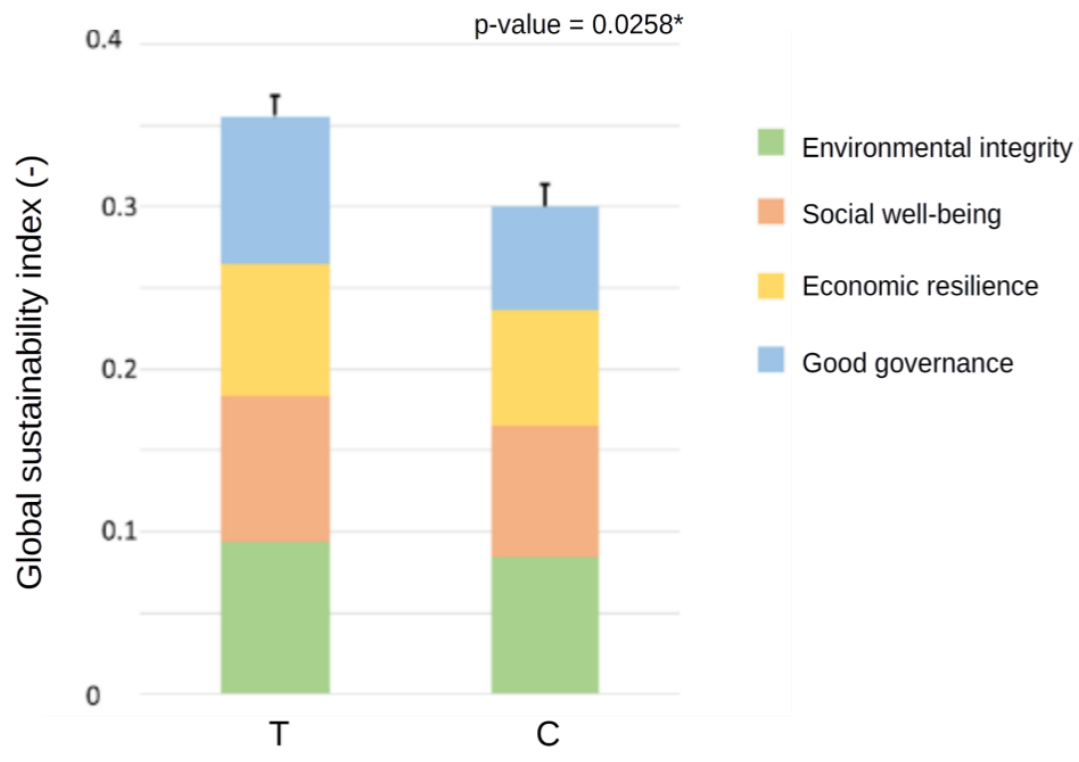

Figure 3. Global sustainability index and its components for both the target $(\mathrm{T})$ and the control (C) groups. The mean value is significantly different between the two groups

Investigations also revealed that $97.5 \%$ of the interviewed target farmers were satisfied or very satisfied by training delivered by the project. An overwhelming majority (95\%) of the interviewees never followed other agricultural trainings than those delivered, which highlighted the impact of those specific project training.

\section{Discussion}

\subsection{Contrasted Agricultural Practices between the Groups}

All these results suggest that, while comparable, both groups significantly differed from sustainable agriculture practices point of view. The target group leads the control group on the scale of sustainability based on several aspects comprised in all dimensions of sustainability. Despite these findings, we must highlight the fact that it does not necessarily mean that project training (and follow-ups of farmers) are the only cause of these sustainability improvements: mean differences do not necessarily imply causality (see Baker (2016) for a deeper discussion). Since trainings were only proposed to vulnerable farmers, they were always followed on a voluntary basis. This suggests that the target group could be intrinsically different from other vulnerable farmers and that we could not capture the contrast in the pre-interview. For example, they could be more prone to learn new practices and to adapt their activities. The group effect would then (partly) reflect another aspect of the farmer behavior, such as the willingness to benefit from training. Behavioral differences between the groups could therefore explain why untargeted sub-themes revealed surprising group-averaged differences, such as the greenhouse gas reduction or conflict resolution which were not directly targeted by the interventions.

Interestingly, most of the indicators, sub-themes and themes emerging from the analysis were seen a priori as targeted by project trainings and follow-ups, which reinforced the idea that trainings and follow-ups provided by the field staff were at least one of the explanatory variables of the observed differences. Some of the themes presenting statistical differences had been observed in other similar studies, such as the biodiversity link to larger food production diversity (McLaughlin 1995) and the decent livelihood, due to increased incomes resulting from more diverse and marketable products (Bechini and Castoldi 2009). More generally, all themes that revealed significant differences (bar one) were directly targeted by the successive projects and correspond to the core of the development plan (capacity building, food sovereignty, long-term management plan, risk management reduction etc.).

Our analysis also suggests that smallholder farming practices remain far from being sustainable. The sustainability of the smallholder farming practices in Kampong Thom province was assessed low: the mean value of the global sustainability index for both groups was close to 0.3 , almost equally distributed in the four pillars for both groups. Core-indicators, themes and sub-themes were almost systematically classified as low- to 
very low, which corresponds to unsustainable agriculture practices. This indicated that even though trainings could increase agricultural sustainability, the situation was far from ideal from an agriculture sustainability standpoint. The study also revealed the deep lack of agricultural knowledge of farmers of both groups. The number of irrelevant replies to mitigation action against risks, for example, was a concrete illustration of the low level of qualification of farmers on some topics in the studied area, and potentially also across the province. As stressed in previous sections, few other organizations deliver farming practices training to farmers in this region, at least in the studied communes and villages. So much work remains to fill the gap of sustainable farming practices in the area and improve the local agricultural sustainability.

\subsection{Limitations of the Present Study}

When investigating sustainability, many changes are time-consuming and the effects of new practices can sometimes only be seen on long-term time scales. Our study took place five years after the project launch (2011), which might be too early for some of the new practices to emerge and benefit the farmers. As about one quarter of the target group of farmers interviewed followed trainings and received support just one year before our analysis took place (which allowed us to reach a higher number of interviewees in a larger area) this may have mitigated the result significance. Repeated investigations over time to similar sampling groups would allow assessment of whether the differences increase (benefits would then accumulate and diversify) or vanish (sustainable agriculture practices would be progressively given up) over time.

As explained in the introduction, several categories of indicators exist, each of them presenting pros and cons. We almost exclusively used target-based and practice-based indicators because they could be easily estimated using interviews, and these indicators did not require any scientific experiments (i.e. in laboratory) or specific scientific skills that field staff did not possess. The choice was made to provide the Cambodian organization with the capacity to quantitatively assess the benefits of their project by associating them with each step of the study (from the choice of methodology to the statistical analysis). Unfortunately, because of the original choice of indicators, we could only mainly assess whether farmers intended to act in the future or whether they already took action to adapt their practices, and not whether positive results happened from their behavior change (de Olde et al. 2016). As we did not use many performance-based indicators, we did not measure much effective sustainability consequences of such practices or action plans. Furthermore, the choice of selecting field staff for conducting the interviewees could have introduced biases in the results. Potentially driven by their willingness to prove the positive impact of their action, staff members may have been tempted to 'force' some answers and induce results. To minimize this threat, we distributed the field facilitators into villages where they were not initially involved in the training and where therefore they interviewed people they did not know personally.

Another weakness of this study is the indicator selection that was necessary in the early beginning of the process. If some core indicators clearly did not make sense for smallholder farmers with a familial structure (see SAFA recommendation), others had to be set aside for different reasons. Some required concepts deemed difficult to understand for low qualified workers (or even for project staff members) and were consequently forgotten in our study, while others were voluntarily withdrawn because of the local political context, which partially explains why so few core indicators belonged to the good governance pillar. Finally, a trade-off was found between the number of indicators to assess and the logistics to perform the study. Therefore, the number of questions and the resulting the number of indicators was limited because we could not afford to spend more than 3 hours with each interviewed farmer. In addition, it should be stressed that post-processing steps, including data translation, encoding and verification were also time-consuming for project staff with frequent calls to farmers for clarification and sometimes revisits to villages to complete questionnaires.

\subsection{Further Directions}

Recent publications illustrated the use of the SAFA framework to assess local agricultural sustainability, for example the work of Gayatri, Gasso-tortajada, and Vaarst (2016) in Indonesia and Omare (2014) in Kenya. Our work follows in the footsteps of such studies. We suggested a novel adaptation of the FAO methodology using questionnaires and collaboration between researchers and development organization members in an original context (i.e. to assess differences between groups, one group being taught sustainable agriculture practices). SAFA presents many advantages and strengths such as its ease of use, its flexibility, and its exhaustiveness. Despite the criticisms that can be raised against composite and normalized indicators (see OECD (2008) for a complete discussion), SAFA offers a solid framework that can be easily adapted to any part of the value chain and to any region globally. Clearly these strengths (flexibility and exhaustiveness) may also be weaknesses when compared to site-specific methods developed to assess vulnerability (Slätmo, Fischer, and Röös 2017). A comprehensive methodology to evaluate sustainable practices should include a comparison with other 
assessment tools, which was far beyond the scope of this study. However, we refer to Eichler Inwood et al. (2018) for a deep discussion of tool comparison and a guide for interpreting results. While it was not the object of the study to compare evaluation tools, complementary frameworks exist and could have led to contrasted results. In particular, other methods include an analysis of the context (Bosc and Sourisseau 2019; López-Ridaura 2002), are participatory (Khadse et al. 2018) and similarly address different scales (Musumba et al. 2017). Yet, they do not all prescribe the required key indicators (Bezner Kerr et al. 2019) or do not necessarily cover the four dimensions of sustainability (e.g. Ring et al. 2010) and were therefore not retained for this study.

Another side effect of our study (which was promoted from the very beginning) was to give to the local organization the keys to assess by themselves the strengths and weaknesses of their actions using scientific methods. As the staff was involved in each step of the procedure (methodological choice, indicator selection, questionnaire designing and writing, field data collection, data entry, quality control, data cleaning and statistical analyses), the whole methodology should be able to be repeated in the future to assess parts or projects as a whole. Since sustainable agriculture is only one part of their action field, the organization staff already have the intention to transpose the whole study (with a corresponding methodology) to their second main predilection domain: public health.

One of the main take-home messages from the interviews is that the very large majority of farmers shared the desire to make their farming practices more sustainable. However, they also agreed that this transition could not occur without external input and support.

\section{Conclusion}

A methodology to adapt the SAFA agricultural sustainability assessment tool was applied to local farmers of rural Kampong Thom province, Cambodia. This method consisted in selecting relevant indicators of the exhaustive list developed by FAO, transformed them into a questionnaire used in October 2016 to interview two groups (with 40 interviewees per group): a target group made by smallholder farmers recipient of a developing project and a control group constituted by other similar but non-targeted smallholder farmers (control group). Interview responses were then used to measure sustainability indexes at different hierarchical levels. The statistical analysis revealed significant differences between the two groups for 12 core indicators, 8 sub-themes and 6 themes distributed among the four pillars of sustainability. As a result, three of the pillars (social, economic resilience and good governance) significantly differed between the groups and a global sustainability index integrating all the collected information displayed similar results: despite the fact that all hierarchical levels were characterized by low levels of sustainability, the target group displayed significantly more sustainable agriculture practices.

Sustainable agriculture training provided during the project seemed to lead to substantial and measurable benefits for human well-being and economic growth without significant negative impacts for the environment. As many changes and sustainable effects take time, the study also questions the timing and frequency of such analysis to assess differences between groups, as well as the causality between treatments and observed difference means. At the very least, this study allowed an organization to build a framework to quantitatively assess the benefits and weaknesses of their past and on-going projects.

\section{Acknowledgements}

This research was financially supported by the Belgian Directorate-General for Development Cooperation and activities were implemented in Cambodia by MODE with technical support of the University NGO Louvain Coopération au Développement. F.M. and C.M. were supported by Louvain Coopération au Développement as well and are thankful to this organization for its technical support and its confidence.

\section{References}

Baker, M. (2016). Statisticians Issue Warning over Misuse of P Values. Nature, 531(7593), 151-151. https://doi.org/10.1038/nature.2016.19503

Bansok, R., Nang, P., \& Chhim, C. (2011). Agricultural Development and Climate Change: The Case of Cambodia.

Bezner, K., Rachel, S., Young, L., Young, C., Santoso, M. V., Magalasi, M., Entz, M., \&Lupafya, E. (2019). Farming for Change: Developing a Participatory Curriculum on Agroecology, Nutrition, Climate Change and Social Equity in Malawi and Tanzania. Agriculture and Human Values, 36(3), 549-66. https://doi.org/10.1007/s10460-018-09906-x

Bockstaller, C., Laurence, G., Olivier, K., Philippe, G., Marie-Béatrice, G., \& Gérard, G. (2009). Comparison of 
Methods to Assess the Sustainability of Agricultural Systems. A Review. Agronomy for Sustainable Development, 29(1), 223-35. https://doi.org/10.1051/agro:2008058

Bonisoli, L., Galdeano-Gómez, E., Piedra-Muñoz, L., \& Pérez-Mesa, J. C. (2019). Benchmarking Agri-Food Sustainability Certifications: Evidences from Applying SAFA in the Ecuadorian Banana Agri-System. Journal of Cleaner Production, 236(November), 117579. https://doi.org/10.1016/j.jclepro.2019.07.054

Bosc, Pierre-Marie, \& Jean-Michel, S. (2019). Sustainable Rural Livelihoods to Analyse Family Farming Dynamics: A Comparative Perspective. no. special, 25-49.

Diepart, Jean-Christophe. (2010). Cambodian Peasant's Contribution to Rural Development: A Perspective from Kampong Thom Province. Biotechnol. Agron. Soc. Environ., 14(2), 321-40.

Eichler, I., Sarah, E., Santiago, López-Ridaura, Keith, L. K., Bruno, G., Andrea, G. M., Bram, G., \& Virginia, H. D. (2018). Assessing Sustainability in Agricultural Landscapes: A Review of Approaches. Environmental Reviews, 26(3), 299-315. https://doi.org/10.1139/er-2017-0058

FAO. (1989). The State of Food and Agriculture: World and Regional Reviews, Sustainable Development and Natural Resource Management. FAO.

. (2013). SAFA Guidelines, Version 2.0. Food and Agriculture Organization of the United Nations. Retrieved from http://www.fao.org/3/a-i3957e.pdf

- (2017). A Literature Review on Frameworks and Methods for Measuring and Monitoring Sustainable Agriculture.

. (2018). FAOSTAT : Cambodia. Retrieved from http://www.fao.org/faostat/en/\#country/115

Gayatri, S., Vincent, Gasso-tortajada, \& Mette, V. (2016). Assessing Sustainability of Smallholder Beef Cattle Farming in Indonesia: A Case Study Using the FAO SAFA Framework. Journal of Sustainable Development, 9(3), 236. https://doi.org/10.5539/jsd.v9n3p236

Hayati, D., Zahra, R., \& Ezatollah, K. (2010). Measuring Agricultural Sustainability. In: Eric Lichtfouse (Ed.), Biodiversity, Biofuels, Agroforestry and Conservation Agriculture (pp. 73-100). Dordrecht: Springer Netherlands. https://doi.org/10.1007/978-90-481-9513-8_2

Hřebíček, J., Oldřich, F., Edward, K., \& Oldřich, T. (2015). Determinants of Sustainability Reporting in Food and Agriculture Sectors. Acta Universitatis Agriculturae et Silviculturae Mendelianae Brunensis, 63(2), 539-52. https://doi.org/10.11118/actaun201563020539

Jawtusch, J., Christian, S., Matthias, S. L. B., \& Urs, N. (2013). Sustainability Monitoring and Assessment Routine: Results from Pilot Applications of the FAO SAFA Guidelines.

Khadse, A., Peter, M. R., Helda. M., \& Bruce, G. F. (2018). Taking Agroecology to Scale: The Zero Budget Natural Farming Peasant Movement in Karnataka, India. The Journal of Peasant Studies, 45(1), 192-219. https://doi.org/10.1080/03066150.2016.1276450

Latruffe, Laure, Ambre Diazabakana, Christian Bockstaller, Yann Desjeux, John Finn, Edel Kelly, Mary Ryan, and Sandra Uthes. (2016. "Measurement of Sustainability in Agriculture: A Review of Indicators." Studies in Agricultural Economics 118 (3): 123-30. https://doi.org/10.7896/j.1624

Lebacq, T., Philippe, V. B., \& Didier, S. (2013). Sustainability Indicators for Livestock Farming. A Review. Agronomy for Sustainable Development, 33(2), 311-27. https://doi.org/10.1007/s13593-012-0121-x

López-Ridaura, S. (2002). Evaluating the Sustainability of Complex Socio-Environmental Systems. the MESMIS Framework. Ecological Indicators, 2(1-2), 135-48. https://doi.org/10.1016/S1470-160X(02)00043-2

Miyan, M. A. (2015). Droughts in Asian Least Developed Countries: Vulnerability and Sustainability. Weather and Climate Extremes, SI: IGBP APN, 7(March), 8-23. https://doi.org/10.1016/j.wace.2014.06.003

Musumba, M., Philip, G., Cheryl, P., \& Sieglinde, S. (2017). Guide for the Sustainable Intensification Assessment Framework.

National Institute of Statistics. (2014). Census of Agriculture in Cambodia 2013: Preliminary Report National. Ministry of Planning \& Ministry of Agriculture, Forestry and Fisheries.

OECD. (2008). Handbook on Constructing Composite Indicators: Methodology and User Guide. Retrieved from https://www.oecd.org/sdd/42495745.pdf. 
Olde, E. M. de, Frank, W. O., Claus, A. G. S., Eddie, A. M. B., \& Imke, J. M. de B. (2016). Assessing Sustainability at Farm-Level: Lessons Learned from a Comparison of Tools in Practice. Ecological Indicators, 66(July), 391-404. https://doi.org/10.1016/j.ecolind.2016.01.047

Omare, B. (2014). Sustainability Assessment of Smallholder Coffee Farmers in Nyeri and Kisii. Budapest, Hungary: Central European University.

Paracchini, M. L., Claudia, B., Giorgio, B., Ernesto, T., Alessandro, B., Danilo, B., Graziano, R., Gilberto, P., Roberto, O., \& Claudio, De P. (2015). A Diagnostic System to Assess Sustainability at a Farm Level: The SOSTARE Model. Agricultural Systems, 133(February), 35-53. https://doi.org/10.1016/j.agsy.2014.10.004

Ring, I., Bernd, H., Thomas, E., Heidi, W., \& Pavan, S. (2010). Challenges in Framing the Economics of Ecosystems and Biodiversity: The TEEB Initiative. Current Opinion in Environmental Sustainability, 2(1-2), 15-26. https://doi.org/10.1016/j.cosust.2010.03.005

Royal Government of Cambodia, and Ministry of Planning. (2013). Annual Progress Report 526 Achieving the Millenium Development Goals Report Prepared on the Status in 2013.

Slätmo, E., Klara, F., \& Elin, R. (2017). The Framing of Sustainability in Sustainability Assessment Frameworks for Agriculture: Framing of Sustainability. Sociologia Ruralis, 57(3), 378-95. https://doi.org/10.1111/soru.12156

Soldi, A., Maria, J. A. M., Marianna, G., Michele, D., \& Amado, I. O. (2019). Sustainability Assessment of Agricultural Systems in Paraguay: A Comparative Study Using FAO's SAFA Framework. Sustainability, 11(13), 3745. https://doi.org/10.3390/su11133745

Srean, P., Buntha, E., Ratha, R., \& Robert, J. M. (2018). Paddy Rice Farming Practices and Profitability in Northwest Cambodia. Asian Journal of Agricultural and Environmental Safety, 1, 1-5.

The World Bank. (2015). Cambodian Agriculture in Transition: Opportunities and Risks. Retrieved from http://documents.worldbank.org/curated/en/805091467993504209/pdf/96308-ESW-KH-White-cover-P1458 38-PUBLIC-Cambodian-Agriculture-in-Transition.pdf

—. (2018). World Development Indicators. Retrieved from https://databank.worldbank.org/source/world-development-indicators.

Werf, H. M. G. van der, Claver, K., \& Michael, S. C. (2009). An Operational Method for the Evaluation of Resource Use and Environmental Impacts of Dairy Farms by Life Cycle Assessment. Journal of Environmental Management, 90(11), 3643-52. https://doi.org/10.1016/j.jenvman.2009.07.003

Werf, H. M. G. van der, \& Jean, P. (2002). Evaluation of the Environmental Impact of Agriculture at the Farm Level: A Comparison and Analysis of 12 Indicator-Based Methods. Agriculture, Ecosystems \& Environment, 93(1-3), 131-45. https://doi.org/10.1016/S0167-8809(01)00354-1

WHO Representative Office Cambodia. (2019). Climate Change and Health. http://www.wpro.who.int/cambodia/topics/climate_change/en/

Yusuf, A. A. (2010). Hotspots! Mapping Climate Change Vulnerability in Southeast Asia. IRSA.

\section{Appendix A}

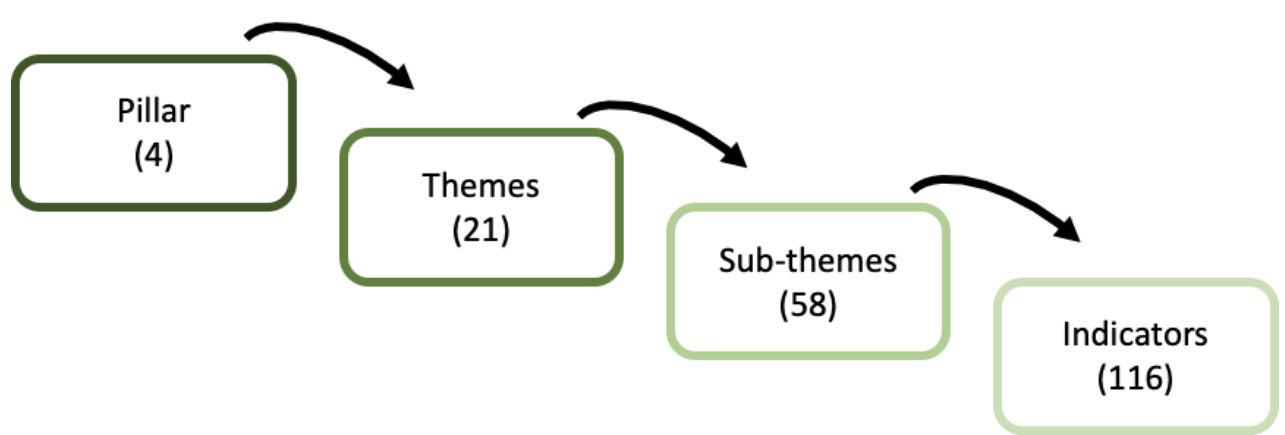

Figure A.1. Schematic overview of the hierarchical levels in the SAFA framework. Adapted from FAO (2013) 
Table A.1. List of sub-themes contained in the SAFA method, categorized by themes and pillars. The last two columns indicate if the corresponding sub-theme is regarded by MODE/Louvain Cooperation project and the significance of the mean comparison between project target farmers and other similar farmers

\begin{tabular}{|c|c|c|c|c|}
\hline Pillars & Themes & Sub-themes ${ }^{1}$ & Project $^{2}$ & Result $^{3}$ \\
\hline \multirow[t]{13}{*}{ Environmental integrity } & E.1 Atmosphere & E.1.1 Greenhouse gases & - & $*$ \\
\hline & & E.1.2 Air quality & - & \\
\hline & E.2 Water & E.2.1 Water withdrawals & - & \\
\hline & & E.2.2 Water quality & - & \\
\hline & E.3 Land & E.3.1 Soil quality & + & \\
\hline & & E.3.2 Land degradation & + & \\
\hline & E.4 Biodiversity & E.4.1 Ecosystem diversity & - & \\
\hline & & E.4.2 Species diversity & + & \\
\hline & & E.4.3 Genetic diversity & + & \\
\hline & E.5 Material and energy & E.5.1 Material use & + & \\
\hline & & E.5.2 Energy use & - & \\
\hline & & E.5.3 Waste reduction and disposal & o & \\
\hline & E.6 Animal welfare & E.6.1 Health and Freedom from stress & + & \\
\hline \multirow[t]{16}{*}{ Social well-being } & S.1 Decent livelihood & S.1.1 Right to quality of life & & \\
\hline & & S.1.2 Capacity building & + & $* * *$ \\
\hline & & $\begin{array}{l}\text { S.1.3 Right of fair access to land } \\
\text { and means of production }\end{array}$ & o & \\
\hline & S.2 Fair trading practices & S.2.1 Responsible buyers & - & \\
\hline & S.3 Labor right & S.3.1 Employment relation & - & \\
\hline & & S.3.2 Forced labor & & \\
\hline & & S.3.3 Child labor & - & \\
\hline & & S.3.4 Employees' freedom of & & \\
\hline & & association and right to bargaining & & \\
\hline & S.4 Equity & S.4.1 Non-discrimination & & \\
\hline & & S.4.2 Gender equality & & \\
\hline & & S.4.3 Support to vulnerable people & & \\
\hline & $\begin{array}{l}\text { S.5 Human health, } \\
\text { safety and happiness }\end{array}$ & $\begin{array}{l}\text { S.5.1 Workplace safety and health } \\
\text { provision for employees }\end{array}$ & - & \\
\hline & & S.5.2 Public health & + & * \\
\hline & S.6 Cultural & S.6.1 Indigenous knowledge & & \\
\hline & development & S.6.2 Food sovereignty & + & $* * *$ \\
\hline \multirow[t]{14}{*}{ Economic resilience } & C.1 Investment & C.1.1 Internal investment & + & \\
\hline & & C.1.2 Community investment & + & \\
\hline & & C.1.3 Long-ranging investment & + & $*$ \\
\hline & & C.1.4 Profitability & + & \\
\hline & C.2 Vulnerability & C.2.1 Stability of supply & - & \\
\hline & & C.2.2 Stability of markets & - & \\
\hline & & C.2.3 Liquidity & + & \\
\hline & & C.2.4 Risk management & + & $*$ \\
\hline & & C.2.5 Stability of production & & \\
\hline & C. 3 Products quality & C.3.1 Food safety & - & \\
\hline & and information & C.3.2 Food quality & - & \\
\hline & & C.3.3 Products information & & \\
\hline & C.4 Local economy & C.4.1 Value creation & + & \\
\hline & & C.4.2 Local procurement & & \\
\hline \multirow[t]{7}{*}{ Good governance } & G.1 Corporate ethics & G.1.1 Mission statement & & \\
\hline & & G.1.2 Due diligence & & \\
\hline & G.2 Accountability & G.2.1 Holistic audits & & \\
\hline & & G.2.2 Responsibility & & \\
\hline & & G.2.3 Transparency & & \\
\hline & G.3 Participation & G.3.1 Stakeholder dialogue & & \\
\hline & & G.3.2 Grievance procedure & & \\
\hline
\end{tabular}




\begin{tabular}{llll}
\hline & G.3.3 Conflict resolution & - \\
G.4 Rules of Law & G.4.1 Legitimacy & \\
& G.4.2 Remedy, restoration and prevention & & \\
& G.4.3 Civic responsibility & & $*$ \\
& G.4.4 Resources appropriation & - & $* * *$ \\
G.5 Holistic & G.5.1 Sustainability management plan & + \\
management & G.5.2 Full cost accounting & \\
\hline
\end{tabular}

Note. ${ }^{1}$ Omitted in our analysis // Taken into account in our analysis

${ }^{2}+$ expected project outcomes, - no expected project outcomes, o priority future project target

$3 *$ significant at $\mathrm{p}=0.05, * * *$ significant at $\mathrm{p}=0.01$

Table A.2. List of core indicators of the SAFA method

\begin{tabular}{|c|c|}
\hline Pillars & Core indicators (SAFA indicators) \\
\hline \multirow{30}{*}{ Environmental integrity } & E 1.1.1 GHG reduction target \\
\hline & E 1.1.2 GHG mitigation practices \\
\hline & E 1.2.1 Air pollution reduction target \\
\hline & E 1.2.2 Air pollution prevention practices \\
\hline & E 2.1.1 Water conservation target \\
\hline & E 2.1.2 Water conservation practices \\
\hline & E 2.1.3 Ground and surface water withdrawals \\
\hline & E 2.2.1 Clean water target \\
\hline & E 2.2.2 Water pollution prevention practices \\
\hline & E 3.1.1 Soil- improvement practices \\
\hline & E 3.1.3 Soil chemical quality \\
\hline & E 3.1.5 Soil organic matter content \\
\hline & E 3.2.1 Land conservation and rehabilitation plan \\
\hline & E 3.2.2 Land conservation and rehabilitation practices \\
\hline & E 4.1.3 Structural diversity of ecosystems \\
\hline & E 4.1.4 Ecosystem connectivity \\
\hline & E 4.1.5 Land-use and land-cover change \\
\hline & E 4.2.1 Species conservation target \\
\hline & E 4.2.2 Species conservation practices \\
\hline & E 4.2.4 Diversity of production \\
\hline & E 4.3.5 Saving of seeds and breeds \\
\hline & E 5.1.4 Intensity of material use \\
\hline & E 5.2.1 Renewable energy use target \\
\hline & E 5.2.3 Energy consumption \\
\hline & E 5.2.4 Renewable energies \\
\hline & E 5.3.1 Waste reduction target \\
\hline & E 5.3.2 Waste reduction practices \\
\hline & E 5.3.4 Food loss and waste reduction \\
\hline & E 6.1.1 Integrated animal health practices \\
\hline & E 6.1.5 Animal health \\
\hline \multirow{8}{*}{ Social well-being } & S.1.2.1 Capacity building \\
\hline & S.1.3.1 Right of fair access to land and means of production \\
\hline & S.2.1.1 Suppliers' freedom of association and right to collective bargaining \\
\hline & S.3.1.1 Employment relation \\
\hline & S.3.3.1 Child labor \\
\hline & S.5.1.1 Workplace safety and health provision for employees \\
\hline & S.5.2.1 Public health \\
\hline & S.6.2.1 Food sovereignty \\
\hline
\end{tabular}




\begin{tabular}{ll}
\hline & C 1.1.1 Internal investment \\
C 1.2.1 Community investment \\
C 1.3.1 Long-term profitability \\
C 1.4.1 Net income \\
C 1.4.3 Price determination \\
C 2.1.1 Procurement channels \\
Economic resilience 2.2 .1 Stability of market \\
C 2.3.2 Safety nets \\
C 2.4.1 Risk management \\
C 3.1.2 Hazardous pesticides \\
C 3.2.1 Quality standards \\
C 4.1.1 Regional workforce \\
G.3.3.1 Conflict resolution \\
G.4.4.1 Free, prior and informed consent \\
G.5.1.1 Sustainability management plan \\
\hline
\end{tabular}

\section{Copyrights}

Copyright for this article is retained by the author(s), with first publication rights granted to the journal.

This is an open-access article distributed under the terms and conditions of the Creative Commons Attribution license (http://creativecommons.org/licenses/by/3.0/). 